\title{
Comprehensive abortion care in the Tain District of Ghana: an analysis of DHIMS- 2 data for 2010-2016
}

\author{
Michael R. Adjei ${ }^{1}$,Kwaku P. Asante ${ }^{2}$, Janet V. Baafi ${ }^{3}$ and Timothy S. Letsa ${ }^{4}$
}

Ghana Med J 2018; 52(4):189-195 doi: http://dx.doi.org/10.4314/gmj.v52i4.5

\author{
${ }^{1}$ Tain District Health Directorate, Ghana Health Service, Nsawkaw, Ghana \\ ${ }^{2}$ Kintampo Health Research Centre, Kintampo, Ghana \\ ${ }^{3}$ Kwahu South District Hospital, Ghana Health Service, Atibie-Kwahu, Ghana \\ ${ }^{4}$ Volta Regional Health Directorate, Ghana Health Service, Ho, Ghana
}

\author{
Corresponding author: Michael R Adjei \\ Conflict of interest: None declared \\ E-mail: bonnahk10@gmail.com
}

\section{SUMMARY}

Background: Access to safe abortion services reduces incidence of unsafe abortion. However, other studies have documented negative impacts such as rise in sexually transmitted infections in jurisdictions with liberal abortion laws.

Objective: We assessed the impact of Comprehensive Abortion Care (CAC) services on selected reproductive health indicators in the Tain district.

Method: Aggregated service data on abortion, contraception (family planning), and delivery antenatal Human Immuno-deficiency Virus (HIV) infection status of women age 10-49 years were extracted from the District Health Information Management System version 2 (DHIMS-2) database for the period 2010 to 2016. Data were converted to rates using projected population figures from the Ghana Statistical Service and presented as tables and graph for trend analysis.

Results: The proportion of unsafe abortion increased from 2010 to 2012 and declined from 2013 onwards with increasing proportions of women opting for safe induced abortions; while spontaneous abortions followed an incremental trend from 2010 to 2013; leveling out from 2014. The family planning acceptor rates stayed above $38 \%$ over the period. The total fertility rate (women age 10-14 inclusive) increased sequentially from 4.6/1000 women in 2010 to $89.4 / 1000$ in 2016 . The HIV infection prevalence were $2.2 \%, 3.7 \%, 3.4 \%, 3.8 \%, 2.5 \%, 2.3 \%$ and $2.7 \%$ for 2010 to 2016 respectively.

Conclusion: Access to Comprehensive Abortion Care (CAC) services reduces the incidence of unsafe abortions. Improved access to contraception may not necessarily lead to a decline in abortion or fertility rates. Liberalizing abortion does lead to a rise in the prevalence of sexually transmitted infections (HIV).

Funding: No external funding received

Keywords: unsafe abortion, comprehensive abortion care, Tain District, DHIMS 2.

\section{INTRODUCTION}

The World Health Organization (WHO) defines unsafe abortion as a procedure for terminating an unintended pregnancy carried out either by persons lacking the necessary skills or in an environment that does not conform to minimal medical standards or both. ${ }^{1}$ Globally, an estimated 56.3 million abortions occurred each year over the period 2010-2014 out of which over $85 \%$ occur in middle and low income countries. ${ }^{2,3}$

In this same period, an estimated $55 \%$ of all abortions were safe, $31 \%$ were less safe, and $14 \%$ were least safe. Safe abortion is when termination of pregnancy is done by qualified person in an environment conforming to minimum medical standards.
A less safe abortion is one that meets only one of the criteria and least safe satisfies none. These proportions differ dramatically by major region. When we combine the less- and least-safe abortions into one category, an estimated $12 \%$ of abortions in the developed world (primarily in Eastern Europe) and $49 \%$ of those in the developing world are considered unsafe. These proportions translate to more than 25 million unsafe abortions per year, virtually all (97\%) of which are in the developing world. ${ }^{4,5}$

WHO issued technical guidance in 2003 to strengthen the capacity of health systems to provide safe abortion care (SAC) and post-abortion care (PAC) as a move aimed at reducing mortality and morbidity associated 


\section{Original Article}

with abortions. ${ }^{6} \mathrm{PAC}$ is the global strategy to reduce death and suffering from the complications of unsafe and spontaneous abortion and comprises five elements namely: treatment; counseling; contraception; linkage to reproductive and other health services; and communityprovider partnership. ${ }^{6}$

Comprehensive abortion care (CAC) includes all of the elements of PAC as well as safe induced abortion for all legal indications (i.e. as allowed by national law). ${ }^{6}$ Making abortion legal, safe, and accessible does not appreciably increase demand. Instead, the principal effect is shifting previously clandestine, unsafe procedures to legal and safe ones. Hence, governments need not worry that the costs of making abortion safe will overburden the health-care infrastructure. ${ }^{7}$

Treatment of abortion complications burdens public health systems in the developing world. Conversely, ensuring women's access to safe abortion services lowers medical costs for health systems. ${ }^{8}$ Direct costs include health personnel, medications, blood, supplies and equipment, and overnight stays. In Kenya, it takes an average of 7.4 hours and $\$ 58$ to manage a woman with complications of unsafe abortion. ${ }^{9}$ The cost is even higher in Sierra Leone where an average of $\$ 68$ is required and government spends $\$ 23100$ annually to treat such cases. This cost could be reduced by $53 \%$ with a shift to safe abortion services. ${ }^{10}$

In recent times, abortion has received considerable attention, and its legality and availability have often generated controversy. Gruber et al. (1999) show that the child who would have been born had abortion remained outlawed was $60 \%$ more likely to live in a single parent household. ${ }^{11}$ Being raised by a single parent is a strong predictor of earlier sexual activity and unprotected sex, evidenced by the higher rates of teenage pregnancy among the poor. ${ }^{12,13}$

According to Klick and Stratmann (2003) and Levine and Staiger (2004) abortion effectively serves an insurance function. Thus, if individuals are forward looking when making decisions regarding their sexual behavior, lowering the cost of abortion through legalization, subsidization, or technological progress that improves the safety of abortions will lead to an increase in risky sexual activity, on the margin, as individuals both have more sex and substitute away from birth control measures..$^{14,15}$

There is longstanding debate in reproductive health circles about the relationship between modern contraception use and abortion. Globally, contraceptive use and abortion rates have been inversely related over the past several decades. ${ }^{16,17}$ However population scholars have documented concomitant increases in both contracep- tive prevalence and abortion rates around the world in settings as diverse as Cuba, South Korea, Bangladesh Singapore, Netherlands, Denmark, and the United States. ${ }^{18}$ This phenomenon is commonly attributed to rapid reductions in desired fertility, which in turn increase demand for all methods of birth control. ${ }^{18}$

In Ghana, the abortion law enacted in 1985 permits abortion in cases if the pregnancy is the result of rape, incest or "defilement of a female idiot;" if continuation of the pregnancy would risk the life of the woman or threaten her physical or mental health; or if there is a substantial risk the child would suffer from a serious physical abnormality or disease ${ }^{19}$. Despite the liberalization of abortion, poor record keeping, reluctance of health workers to appropriately classify abortion and social stigmatization often lead to underreporting of induced abortions. ${ }^{20}$ Generally, the level of abortion in Ghana appears to be lower than in Western Africa as a whole, where the rate stands at 28 procedures per 1,000 women. ${ }^{21}$ One study conducted in southern Ghana observed a rate of 17 abortions per 1000 women in their reproductive age. ${ }^{22}$

To ensure that legal abortions are provided safely, the Ghana Health Service and the Ministry of Health established protocols for the provision of safe abortion services. These guidelines, adopted in 2006, outline the components of comprehensive abortion care and call for expanding the base of health providers to perform firsttrimester procedures. ${ }^{23}$ Ghana's liberal law notwithstanding, as of 2007 a mere $3 \%$ of pregnant women and only $6 \%$ of those seeking an abortion were aware of the legal status of abortion. Almost half (45\%) of abortions in Ghana remain unsafe. ${ }^{23}$

In 2010, a confidential enquiry conducted in some communities in the Tain District revealed that many women suffered complications of unsafe abortion while others lost their lives. ${ }^{24}$ These findings necessitated the introduction of CAC services in the District Hospital in 2010 as part of measures instituted to drastically reduce maternal deaths.

Overcoming challenges of access led to the introduction of services in the sub-district facilities in 2013 following training of middle level providers (midwives) with support from a Non-Governmental Organization (NGO). ${ }^{24}$ We assess the impact of CAC services on some reproductive health indicators in the District using aggregated routine service data collected from 2010 to 2016.

\section{METHODS}

\section{Study area}

Tain District is one of the 27 administrative districts in the Brong Ahafo Region of Ghana. The estimated population for 2017 was 103,680 (annual growth rate was 
$2.3 \%$ ) with $23.8 \%$ constituting women in reproductive age. ${ }^{25}$ The District has five urban settlements namely Badu with a population of 13,021 , Seikwa $(10,471)$, Debibi $(7,318)$, Nsawkaw $(6,342)$ and Brohani $(6,105)$. The rest of the population may be described as rural, living in communities with population less than 5,000. There are four sub-districts and these are Nsawkaw, Badu, Seikwa and Debibi. ${ }^{25}$

There are a total of 11 health facilities comprising a hospital, 4 Health Centers, 5 Community-based Health Planning and Services (CHPS) Compounds and two Private Maternity Home / Clinic. There are 29 demarcated functional CHPS zones and 123 communities all with volunteers involved in service delivery. Six health facilities (Nsawkaw hospital; Debibi, Brodi, Seikwa, and Badu Health Centres; and Brohani CHPS) provide comprehensive abortion care (CAC) services as part of reproductive health package.

Nsawkaw Hospital and Brohani CHPS are located in the Nsawkaw sub-district; Badu Health Centre in the Badu sub-district; Debibi and Brodi Health Centres in the Debibi sub-district; and Seikwa Health Centre in the Seikwa sub-district. We conducted a descriptive ecological study in the Tain District using aggregated service data for family planning, abortion, delivery and Human Immuno-deficiency Virus (HIV) infection status of pregnant women attending antenatal care extracted from the District Health Information Management System version 2 (DHIMS-2) for the period 2010 to 2016.

DHIMS-2 is free open source software that was first introduced in Ghana in the year 2007 and is primarily used for collecting and reporting health data generated at all levels of care. ${ }^{25}$ With unique passwords, managers access data to make informed decisions on health delivery within their areas of operation.

The data is also accessible to multi-national health partners. Data is collected at health facility level using standard registers and collated on summary forms and entered onto the platform monthly. The standard registers are provided for all services rendered by health facilities based on the level of care and the variables collected depends largely on the purpose of the data.

The aggregates were verified from the primary sources (comprehensive abortion care logbooks, family planning, antenatal and postnatal clinics registers of all the service centres) through physical counts to ensure agreement with DHIMS-2 database. Where there were disparities the source data was taken. The average data completeness and consistency between primary source and DHIMS-2 were 93\% and 95\% respectively. Data was extracted onto Microsoft Excel sheet for computation of rates and proportions.
Anonymity and confidentiality was strictly ensured and data kept under lock and key.

Variables collected include number of abortions by person (age group:10-14, 15-19, 20-24, 25-29, 30-35, 35+), type ( Safe induced, Unsafe induced and Spontaneous), place (sub-district), and time (year); family planning acceptor rate by person and time; delivery by time and person; and HIV status of pregnant women age 1049 by time. HIV was used as a proxy for sexually transmitted infection (STI) as it is the STI commonly tested and entered onto DHIMS-2 by all health facilities in the district. The age group 35+ covered women 35-49 years.

Unsafe induced abortion is defined as termination of pregnancy by unqualified persons and or in an environment lacking the minimum medical standards. Safe induced abortion is the termination of pregnancy by qualified persons in an environment conforming to minimum standards. ${ }^{1}$ Spontaneous abortion is the unintended loss of pregnancy before viability. ${ }^{26}$ Classification of the type of abortion was done by the care provider based on history from the client. Population data for the denominators were obtained from the population projections produced by Ghana Statistical Service. ${ }^{27}$

Ethical approval was sought from Kintampo Health Research Centre Institutional Ethics Committee (KHRCIEC). Administrative permission was sought from Regional and District Directors of Health for Brong Ahafo Region and Tain District respectively.

\section{Data analysis}

Age-specific abortion rates were calculated by dividing the number of abortions by the number of women in reproductive age (WIRA) for each age group and multiplying by 1000 . The total annual abortion rates were calculated in a similar approach. Proportion of abortion attributable to each age group for the entire period (2010-2016) was calculated by dividing the total number of abortions occurring in the age group by the total for the period and multiplying by 100 .

Age-specific fertility rates were estimated by dividing the number of births with the number of WIRA for each age group and multiplying by 1000 . The total fertility rate for each year was calculated through similar approach. Proportion of birth attributable to each age group for the entire period was calculated by dividing the total number of births in the age group by total births and multiplying by 100 .

HIV prevalence among pregnant women was calculated by dividing the number of antenatal registrants testing positive with the total registrants and multiplying by 100 . 
Estimates were carried out at 95\% confidence level and figures rounded to one decimal place. Data was presented as tables and graph to depict trends. The impact of CAC services was assessed by the following:

- Trends of the types of abortion: Increasing trend of safe induced abortion with decline in unsafe induced was depictive of positive impact of CAC with the reverse being equivocal.

- Family planning acceptor rates and fertility: Increasing family planning acceptor rate with declining fertility was attributable to access to $\mathrm{CAC}$ with the reverse being equivocal.

- $\quad$ Prevalence of STI (HIV): Rise in HIV prevalence was attributed to liberalization of abortion (CAC) with the reverse being equivocal.

\section{RESULTS}

A total of 1820 cases of abortion were recorded over the period under study (Table 1). The number of cases followed an incremental trend with the highest (522 cases) being recorded in 2016. More than three-quarters of the cases were in the age group 15-29 years with a little over $32 \%$ attributed to women age 15-19 years alone. $58.8 \%(1034)$ of the cases were safe induced abortions while $22.3 \%$ (406) and 20.9\% (380) were unsafe induced and spontaneous abortions respectively.

The proportion of unsafe abortion increased from 2010 to 2012 and declined from 2013 onwards with increasing proportions of women opting for safe induced abortions while spontaneous abortions followed an incremental trend from 2010 to 2013; leveling out from 2014.

Table 1 Abortion (Number of cases N; Abortion rate AR) in Women Age 10-49 Years, by Year-Tain District, 20102016

\begin{tabular}{|l|l|l|l|l|l|l|l|l|}
\hline $\begin{array}{l}\text { AGE } \\
\text { GROUP }\end{array}$ & $\begin{array}{l}\mathbf{2 0 1 0 N} \\
(\mathbf{A R} / \mathbf{1 0 0 0})\end{array}$ & $\begin{array}{l}\mathbf{2 0 1 1 N} \\
(\mathbf{A R} / \mathbf{1 0 0 0})\end{array}$ & $\begin{array}{l}\mathbf{2 0 1 2 N} \\
(\mathbf{A R} / \mathbf{1 0 0 0})\end{array}$ & $\begin{array}{l}\mathbf{2 0 1 3 N} \\
(\mathbf{A R} / \mathbf{1 0 0 0})\end{array}$ & $\begin{array}{l}\mathbf{2 0 1 4 N} \\
(\mathbf{A R} / \mathbf{1 0 0 0})\end{array}$ & $\begin{array}{l}\mathbf{2 0 1 5 N} \\
(\mathbf{A R} / \mathbf{1 0 0 0})\end{array}$ & $\begin{array}{l}\mathbf{2 0 1 6 N} \\
(\mathbf{A R} / \mathbf{1 0 0 0})\end{array}$ & $\begin{array}{l}\text { TOTAL } \\
\text { N(\%) }\end{array}$ \\
\hline $\mathbf{1 0 - 1 4}$ & $0(0)$ & $1(0.2)$ & $1(0.2)$ & $6(1.0)$ & $6(1.0)$ & $3(0.5)$ & $9(1.4)$ \\
\hline $\mathbf{1 5 - 1 9}$ & $0(0)$ & $24(5.3)$ & $76(16.4)$ & $82(17.2)$ & $110(22.7)$ & $111(22.4)$ & $183(36.2)$ & $58(1.4)$ \\
\hline $\mathbf{2 0 - 2 4}$ & $2(0.5)$ & $22(5.7)$ & $63(15.4)$ & $78(19.2)$ & $115(27.7)$ & $118(27.8)$ & $127(29.2)$ & $526(28.9)$ \\
\hline $\mathbf{2 5 - 2 9}$ & $2(0.6)$ & $11(3.0)$ & $36(9.8)$ & $40(10.6)$ & $61(15.8)$ & $59(15.0)$ & $83(19.1)$ & $292(16.0)$ \\
\hline $\mathbf{3 0 - 3 4}$ & $0(0)$ & $12(3.7)$ & $29(9.2)$ & $29(9.0)$ & $36(10.7)$ & $40(11.9)$ & $62(18.0)$ & $208(11.4)$ \\
\hline $\mathbf{3 5}+$ & $0(0)$ & $3(0.7)$ & $16(3.5)$ & $35(7.5)$ & $34(7.1)$ & $37(7.5)$ & $58(11.5)$ & $183(10.1)$ \\
\hline $\begin{array}{l}\text { TOTAL } \\
\text { (NAR/1000) }\end{array}$ & $4(0.1)$ & $73(2.9)$ & $221(8.6)$ & $270(10.2)$ & $363(13.3)$ & $368(13.3)$ & $522(18.3)$ & $1820(100)$ \\
\hline
\end{tabular}

More than three-quarters (1436) of the cases accessed CAC services from the Nsawkaw sub-district with the remaining patronizing services from the Debibi, Seikwa and Badu sub-districts respectively. Majority (93.2\%) of the uterine evacuations were done with manual vacuum aspirator (MVA) and the remainder (6.8\%) with medication (Mifepriston/Misoprostol combination)

A total of 24558 new users of contraceptives were recorded over the period. The proportion of acceptors were $4.2 \% \quad(1026), 14.2 \%$ (3480), 25.4\% (6257), 24.9\% (6112), 18.3\% (4499) and 18.3\% (3184) for age groups 10-14, 15-19, 20-24, 25-29, 30-34 and 35+ respectively. The family planning acceptor rates stayed above $38 \%$ over the period with the lowest $(38.2 \%)$ being recorded in 2013 and the highest (67.8\%) in 2016. 53.7\% of new users opted for short acting reversible devices with remainder patronizing long term reversible. 71.5\% (1302) of women accessing CAC services accepted postabortion contraception.

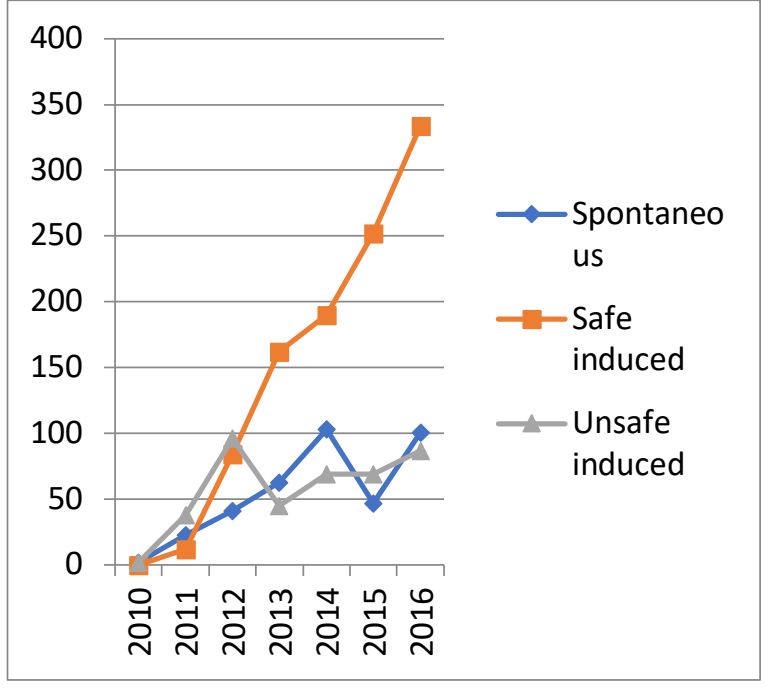

Figure 1 Trend of Abortions by Type in Women Age 10-49 Years-Tain District, 2010-2016 


\section{Original Article}

Table 2 Fertility (Number of births N; Fertility rate FR) in Women Age 10-49 Years, by Year-Tain District, 2010-

\begin{tabular}{|c|c|c|c|c|c|c|c|c|}
\hline AGE & $\begin{array}{l}2010 \\
\text { N(FR/1000) }\end{array}$ & $\begin{array}{l}2011 \\
N(F R / 1000)\end{array}$ & $\begin{array}{l}2012 \\
\text { N (FR/1000) }\end{array}$ & $\begin{array}{l}2013 \\
\text { N(FR/100) }\end{array}$ & $\begin{array}{l}2014 \\
\text { N (FR/1000) }\end{array}$ & $\begin{array}{l}2015 \\
N(F R / 1000)\end{array}$ & $\begin{array}{l}2016 \\
N(F R / 1000)\end{array}$ & $\begin{array}{l}\text { TOTAL } \\
\text { N (\%) }\end{array}$ \\
\hline $10-14$ & $2(0.4)$ & $7(1.2)$ & $13(2.2)$ & $6(3.0)$ & $14(2.3)$ & $11(1.8)$ & $16(2.4)$ & $69(0.50)$ \\
\hline $15-19$ & $39(8.8)$ & $195(43.1)$ & $293(63.4)$ & $319(67.5)$ & $438(90.6)$ & $310(62.7)$ & $315(62.2)$ & 1909 (13.9) \\
\hline $20-24$ & $90(23.8)$ & 435 (114.8) & $644(162.5)$ & $600(148.0)$ & $75(174.7)$ & $607(143.0)$ & 594 (136.8) & 3695 (26.9) \\
\hline 25-29 & $89(25.3)$ & $375(104.1)$ & 478 (129.7) & 634 (168.1) & $758(196.5)$ & 618 (156.6) & 597 (147.9) & $3549(25.8)$ \\
\hline 30-34 & $53(17.7)$ & $218(71.0)$ & $353(112.3)$ & $433(134.7)$ & $581(172.8)$ & $516(153.4)$ & 476 (138.3) & $2630(19.2)$ \\
\hline $35+$ & $23(5.2)$ & $130(29.0)$ & $220(48.0)$ & 294 (62.6) & $397(82.7)$ & $411(83.7)$ & $411(81.8)$ & $1886(13.7)$ \\
\hline $\begin{array}{l}\text { TOTAL } \\
\text { N (FR/1000) }\end{array}$ & $296(4.6)$ & $1360(53.8)$ & $2001(77.2)$ & $2286(86.5)$ & $2913(107.4)$ & $2473(89.4)$ & $2409(84.5)$ & $13738(100)$ \\
\hline
\end{tabular}

A total of 13738 births were recorded over the period with the highest (2913) in 2014 (Table 2). The total fertility rate (women age 10-14 inclusive) increased sequentially from 4.6/1000 (95\% CI: 1.0-8.8/1000) women in 2010 to $89.4 / 1000$ (95\% CI: 71.8-107.1) in 2016. Two-thirds of all births were recorded in the age group $15-29$ with nearly $27 \%$ occurring in women age $20-24$ years alone.

A total of 14112 women age 10-49 years who attended antenatal clinic within the period were tested for HIV and 413 were positive with an average prevalence of $2.9 \%$. The HIV infection prevalence were $2.2 \%, 3.7 \%$, $3.4 \%, 3.8 \%, 2.5 \%, 2.3 \%$ and $2.7 \%$ for 2010 to 2016 respectively.

\section{DISCUSSION}

The rate of abortion increased sequentially from 2010 to 2016. However, with the exception of 2016 the figures were lower than what pertains in Northern America and the Oceania touted to have the lowest abortion rates (17 and 19 per 1000). ${ }^{5}$ The incremental trend of safe in

duced abortions and the fall in unsafe induced abortion lends support to the fact that many women carrying unintended pregnancy hitherto self-induced or obtained clandestine abortions from medical practitioners, ${ }^{28}$ paramedical workers, or traditional healers. ${ }^{27}$

Liberalizing abortion often leads to a rise in cases during the immediate years following decriminalization but declines and stabilizes subsequently. ${ }^{30,21}$ Access to safe abortion services does not increase demand but shifts unsafe abortions to safe ones ${ }^{2,8,32}$ as observed in our study. Prior to the posting of a medical doctor to the district in December, 2010, women accessed abortion care services from neighbouring district and this accounts for the low figure in that year. Again at the inception of CAC services, unsafe induced abortions were high compared to the other types (safe and spontaneous abortions) because a larger section of populace especially women were uninformed ${ }^{21}$ and therefore continued to resort to clandestine means.
The patronage of services by women living in surrounding districts with poor access to CAC services contributed marginally to the soaring of annual figures.

Tain is surrounded by districts with faith based hospitals that offer no safe abortion services except PAC putting women at the 'mercy' of private providers who charge heavily. The exorbitant charges drive them to travel long distance to seek services from the Tain District. One study found out that women living in places with poor access to abortion services often travel great distances to reach a provider. ${ }^{33}$

The cost of procuring safe abortion is highly variable and generally very expensive for many women in settings where few practitioners perform the procedure. ${ }^{19}$ The cost of services (less than two hundred Ghana cedis for all gestations per procedure) was agreed upon by all providers in the district and was regulated by the Health Administration. The emphasis was on providing CAC to women in need hence even those without money were offered free service as a move to stem unsafe abortion. All the women were counseled and given contraception free of charge and this is highly commendable.

The Nsawkaw sub-district recorded more than threequarters of the total abortion cases due to the location of the district hospital and the presence of doctors providing services. This supports the findings that majority of Ghanaian women (57\%) who procure abortion services do so with the help of a qualified medical doctor in a hospital setting. ${ }^{27}$ In addition, it was the hospital that piloted the CAC services in the district and therefore the most popular and preferred centre.

The observation that the highest abortion rate was among women age 15-19 years is consistent with the study findings of Chae et al (2017) among Nigerian women. ${ }^{34}$ This phenomenon is partly explained by the relatively low patronage of contraception (14.2\%) among as shown by our study. The rising age at first marriage combined with increasing levels of premarital sex continues to result in unintended pregnancies among adolescents. 
Again, women in this group are often in school or learning a trade and are not in committed relationships hence the procurement of abortion as a means of dealing with unplanned pregnancies. Evidence from Europe, however demonstrates that societal acceptance of adolescent sexual relationship coupled with contraceptive use often leads to low pregnancy rate and by extrapolation induced abortion among young adults. ${ }^{7}$

Despite the high family planning acceptor rates, total abortion rates were also high. This contradicts the assertion that abortion rates are higher in settings with poor assess to contraceptive services ${ }^{2,34}$ but consistent with the study findings Marston and Cleland. ${ }^{18}$ All health facilities in the district including private offered contraceptives at very low fees determined by the District Health Administration and systems were available to enforce this. It was enhanced by the periodic distribution of free family planning devices by some NGOs and the health facilities in the district. In addition, there are adolescent health corners in all four sub-districts with trained staffs that provide services to cater for the special needs of this group.

The high total abortions and increase in fertility rates in the face of improved access to contraception could be attributed to the type of device patronized and the 'contraception counter campaigns' championed by herbalist and religious groups. Majority of women especially those in the age group 15-19 preferred short term devices such as the injectable (Depo provera and Norigynon) because it is concealed and deemed more convenient. However continuity is poor due to undesirable effects such as absent menses and the myth of being rendered infertile as claimed by some women.

Our study does not support the work of Klick and Stratmann (2003) and Levine and Staiger (2004) who observed that increasing access to abortion through liberalization was associated with increased prevalence of STI. ${ }^{14,15}$ Although HIV infection is transmissible by means other than unprotected sex, the prevalence dropped from $3.8 \%$ in 2013 to $2.7 \%$ in 2016; a period coinciding with the 'decentralization' of CAC services to the sub-districts. This observation could be attributed to the vigorous HIV/AIDS campaign activities embarked upon by the District Health Directorate and the District Assembly in the areas of public education and condom distribution.

A limitation of this study is that we utilized aggregated data of health facilities reporting in the DHIMS 2 database and does not include data from drug vendors and herbalists who may be providing abortion services albeit illegal. In addition, misclassification of abortion types and data entry errors by health workers could potentially affect the quality of data.
Lastly, although HIV is less common than other STIs, it was used as a proxy because it has the most complete data in our database.

\section{CONCLUSIONS}

Access to Comprehensive Abortion Care (CAC) services reduces the incidence of unsafe abortions and by inference abortion related morbidity and mortality. Although it can soar up contraceptive use, the accruing high family planning acceptor rate may not lead to fertility decline.

\section{ACKNOWLEDGEMENT}

We wish to express our sincere gratitude to all staffs of the Tain District Health Directorate for their immense contribution to this work especially Messrs Asare-Ntow Kofi and Elikem Adzomah. We are also grateful Messrs Peter Anlaakuu and Fred Kanyoke of Kintampo Health Research Centre for their assistance. Lastly, we appreciate the support and encouragement of Drs. Kofi Issah and Osei Kuffour Afreh; Regional Director of Health Services and Deputy Director Public Health of Brong Ahafo Region respectively in putting together this work.

\section{REFERENCES}

1. World Health Organization (WHO). Safe abortion: Technical and policy guidance for health systems. 2th ed. Geneva, 2012.

2. Sedgh G, Bearak J, Singh S, Bankole A, Popinchalk A, Ganatra B, et al. Abortion incidence between 1990 and 2014: global, regional, and subregional levels and trends. The Lancet. 2016: 388 (10041):258-267.

3. World Health Organization (WHO). Unsafe abortion: global and regional estimates of the incidence of unsafe abortion and associated mortality in 2000 . 4th edition. Geneva, Switzerland, 2004.

4. Ganatra B et al., Global, regional, and subregional classification of abortions by safety, 2010-14: estimates from a Bayesian hierarchical model, Lancet, 2017, 390(10110):2372-2381.

5. Alan Guttmacher Institute. Abortion worldwide: uneven progress and unequal access. New York: The Alan Guttmacher Institute, 2017.

6. Grimes DA, Benson J, Singh S, Romero M, Ganatra $\mathrm{B}$, Okonofua FE and Shah IH. Unsafe abortion: the preventable pandemic. The Lancet. 2006; 368(9550): 1908-1919.

7. Inter-Agency Field Manual on Reproductive Health in Humanitarian Setting: Revision for Field Review (2010). Comprehensive Abortion Care [Internet]. Available from: https://www.ncbi.nlm.nih.gov/books/NBK305158/

8. Alan Guttmacher Institute. Sharing responsibilities: women, society and abortion worldwide. New York: The Alan Guttmacher Institute, 1999. 
9. Ministry of Health. The cost of treating unsafe abortion complications in public health facilities in Kenya, 2018. Available from https://aphrc.org/wp

10. Paul M, Gebreselassie H, Samai M, Benson J, Kargbo SAS, et al. (2015) Unsafe Abortion in Sierra Leone: An Examination of Costs and Burden of Treatment on Healthcare Resources. J Women's Health Care 4:228. doi:10.4172/21670420.1000228 .

11. Gruber J, Levine PB, and Staiger D. Abortion Legalization and Child Living Circumstances: Who is the "Marginal Child"? Quarterly Journal of Economics 1999; 263-291.

12. Santelli J, Lowry R, Brener N, and Robin L. "The Association of Sexual Behaviors with Socioeconomic Status, Family Structure, and Race/Ethnicity Among US Adolescents," American Journal of Public Health 2000; 1582-1588.

13. Catlainn S, Diclemente RJ, Wingood GM, Crosby R, Cobb B, Harrington K, Davies S, Hook E, and Oh K. Socioeconomic Status and Self-reported Gonorrhea Among African American Female Adolescents, Sexually Transmitted Diseases 2001; 236239.

14. Klick J, and Stratmann T. The Effect of Abortion Legalization on Sexual Behavior: Evidence from Sexually Transmitted Diseases, Journal of Legal Studies 2003; 407-33.

15. Phillip L, and Staiger D. Abortion Policy and Fertility Outcomes: The Eastern European Experience; Journal of Law \& Economics 2004; 223-44.

16. Levchuk N. and Perelli-Harris B. Declining fertility in Ukraine: What is the role of abortion and contraception? MPIDR working paper WP 2009; 045.

17. Alkema L, Kantorova V, Menozzi C and Biddlecom A. National, regional, and global rates and trends in contraceptive prevalence and unmet need for family planning between 1990 and 2015: A systematic and comprehensive analysis. The Lancet. 2013; 381:1642-1652. doi: 10.1016/S01406736(12) 62204 1. [PubMed][Cross Ref]

18. Marston C, Cleland J. Relationships between contraception and abortion: a review of the evidence. Int Fam Plan Perspect 2003; 29: 6-13.

19. Morhee RAS and Morhee ESK, Overview of the law and availability of abortion services in Ghana, Ghana Medical Journal, 2006, 40(3):80-86

20. Mote CV, Otupiri E, Hindin JM. Factors associated with induced abortion among women in Hohoe Ghana. African Journal of Reproductive Health 2010; 14(4):121

21. World Health Organization (WHO). The prevention and management of unsafe abortion: report of a technical working group. Geneva, 1992
22. Ahiadeke $\mathrm{C}$, Incidence of induced abortion in southern Ghana, International Family Planning Perspectives, 2001, 27(2):96-101\&108.

23. Alan Guttmacher Institute. Abortion in Ghana: uneven progress and unequal access. New York: The Alan Guttmacher Institute, 2013.

24. Tain District Health Directorate, Annual Health Report 2012, Nsawkaw, Brong Ahafo Region, Ghana, 2013.

25. Tain District Health Directorate, Annual Health Report 2016, Nsawkaw, Brong Ahafo Region, Ghana, 2017.

26. Medterms Medical Dictionary A-Z list (2016). Medical definition of spontaneous abortion [Internet]. Available from: https://www.medicinenet.com/script/main/art.asp?a rticlekey $=17774$

27. Ghana Statistical Service (GSS), Ghana Health Service (GHS) and Macro International, Ghana Maternal Health Survey 2007, Accra, Ghana: GSS and GHS; and Calverton, MD, USA: Macro International, 2009

28. Okonofua FE, Shittu SO, Oronsaye F, Ogunsakin D, Ogbomwan S and Zayyan M. Attitudes and practices of private medical providers towards family planning and abortion services in Nigeria. Acta Obstet Gynecol Scand 2005; 84: 270-80.

29. Okonofua FE, Odimegwu C, Ajabor H, Daru PH and Johnson A. Assessing the prevalence and determinants of unwanted pregnancy and induced abortion in Nigeria. Stud Fam Plann 1999; 30: 6777.

30. Koonin LM, Smith JC Ramick M and Lawson HW. Abortion surveillance: United States, 1989. MMWR CDC Surveill Summ 1992; 41(5):1-33.

31. Koonin LM, Strauss LT, Chrisman CE, Montalbano MA, Bartlett LA and Smith JC. Abortion surveillance: United States, 1996. MMWR 1999;48(SS04):1-42.

32. Piero R, Colomer C, Alvarez-Dardet C and Ashton JR. Does the liberalization of abortion laws increase the number of abortions? European Journal of Public Health 2001; 11(2): 190-194

33. Henshaw SK, Singh S and Haas T, Recent trends in abortion rates worldwide, International Family Planning Perspectives, 1999, 25(1):44-48.

34. Chae S, Desai S, Crowell M and Sedgh G,Singh S. Characteristics of women obtaining induced abortions in selected low- and middle- income countries. PLoS ONE 2017; 12(3): e0172976.

Available at:

https://doi.org/10.1371/journal.pone.0172976. Accessed on $21 / 01 / 18$ 